\title{
International Classification of Functioning, Disability, and Health in adult and older users of an audiology services
}

Valquíria Conceição Souza1 https://orcid.org/0000-0003-2944-9242

Stela Maris Aguiar Lemos ${ }^{2}$ https://orcid.org/0000-0003-4104-5179

Universidade Federal de Minas Gerais UFMG, Programa de Pós-Graduação em Ciências Fonoaudiológicas, Belo Horizonte, Minas Gerais, Brasil.

2 Universidade Federal de Minas Gerais UFMG, Departamento de Fonoaudiologia, Belo Horizonte, Minas Gerais, Brasil.

Paper carried out as part of the Postgraduate Program in SpeechLanguage-Hearing Sciences, Universidade Federal de Minas Gerais, Belo Horizonte, Minas Gerais, Brazil.

Research support sources: Produtividade em Pesquisa CNPq - PQ 305782/2015-0. Coordenação de Aperfeiçoamento de Pessoal de Nível Superior - Brasil (CAPES) - Finance Code 001

Conflict of interests: Nonexistent

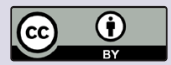

Received on: June 17, 2020

Accepted on: November 19, 2020

Corresponding address:

Stela Maris Aguiar Lemos

Avenida Professor Alfredo Balena, $n^{0} 190$

Sala 251, Santa Efigênia

CEP: 30130-100 - Belo Horizonte

Minas Gerais, Brasil

E-mail: lemos.stela@gmail.com

\section{ABSTRACT}

Purpose: to describe aspects of functioning and disability related to hearing and sociodemographic factors of audiology service users.

Methods: an exploratory study with a probabilistic sample comprising 152 participants who answered a socioeconomic and assistance questionnaire. The functioning and disability were analyzed by means of the International Classification of Functioning, Disability, and Health. Descriptive data analyses were conducted.

Results: most users of the Hearing Health Care Service considered they had mild $(41.2 \%)$ or moderate $(34.2 \%)$ disability in b1560 Auditory perception, and mild $(36 \%)$ and moderate $(35.1 \%)$ disability in b230 Hearing Functions. In Activities and Participation, the users of the Hearing Health Care Service obtained better results in d330 Speaking (83.3\%), d315 Communicating with and receiving nonverbal messages $(65.8 \%)$, and $d 760$ Family relationships $(65.1 \%)$. The hearing aid was a facilitator in these subjects' social interaction with the environment. Most of those attending the Audiology Outpatient Center did not have disabilities or difficulties in the activities and participation, and the environment was a facilitator.

Conclusion: most of the participants attending the Hearing Health Care Service had a disability in auditory perception and hearing functions. However, such a disability was not a limiting factor in the performance of most of the activities and participations assessed.

Keywords: Hearing; International Classification of Functioning, Disability and Health; Hearing Loss; Adult; Aged 


\section{INTRODUCTION}

The World Health Organization (WHO) defines hearing disability as a comprehensive term employed to describe the hearing loss in one or both ears'. According to data released by the Brazilian Geography and Statistics Institute - Instituto Brasileiro de Geografia e Estatística (IBGE), $5.1 \%$ of the Brazilian population has some type of hearing disability².

Hearing loss is mainly assessed with psychoacoustic measures, such as the pure-tone threshold audiometry. However, these alone are not enough to measure the impacts of hearing loss on the person's life ${ }^{3}$.

The consequences of hearing loss are not limited to changes in the structures or functions of the hearingrelated organs. Other implications include emotional changes, decreased ability to understand speech in either silence or noise, limitations in the activities of daily living, and restricted participation in social events and occupational activities ${ }^{4}$. The effects of these consequences vary from person to person and from time to time with any given person ${ }^{4}$.

Using a hearing aid $(\mathrm{HA})$ is one of the options to diminish the effects caused by hearing loss. Its use helps to reduce the harm to body function, limited activities, and participation restrictions. Consequently, the quality of life is given a better assessment ${ }^{5}$.

In 2001, WHO issued the International Classification of Functioning, Disability, and Health (ICF), which since then has had updates and new versions. It describes functioning and disability related to health conditions, in an approach that defines health from a biological, individual, and social standpoint in a multidimensional relationship ${ }^{6}$.

Of the research that used this classification, one study is worth highlighting, whose objective was to investigate the perspective of patients with complaints of dizziness or vertigo. It considered the aspects of functioning and health with the ICF and revealed that most of the activity and participation aspects used for the classification were deemed as restrictions (personal and formal relationships, leisure, work, and community life). The environmental factors related to the codes of sound, climate, temperature, populational density, and architectural designs were deemed as barriers, whereas those related to the family, friends, neighbors, and their attitudes were deemed as facilitators for better social behavior of the person with dizziness or vertigo ${ }^{7}$.

Another piece of research studied the impact of tinnitus in the context of the ICF on adults with auditory thresholds within normal standards, regarding the relationship between the intensity, frequency, and time of the tinnitus onset and the limitations to activity and restrictions to participation. It indicated a low positive correlation between the intensity of the tinnitus and the limitations to activity and restrictions to participation, as well as a negative correlation between the frequency and time of tinnitus onset and the limitations to activity and restrictions to participation. Hence, in the context of the ICF, the presence of tinnitus did not result in significant limitations to activity and restrictions to participation. It is restated, nonetheless, the importance of researching with larger samples and in people with hearing loss ${ }^{8}$.

Using the ICF in clinical practice enables to follow up on people with hearing loss and hearing-related situations in a multidimensional experience ${ }^{9}$. It is possible, then, to obtain the patients' profile, monitor evolution processes, assess the therapeutic practices employed, and measure the disability caused by hearing loss $^{9}$. Concerning hearing, the functioning construct and the ICF can be used in different contexts ${ }^{10}$, such as occupational health ${ }^{11}$ and hearing health regulation services ${ }^{12}$.

Given the above, this study aimed to describe aspects of functioning and disability related to hearing and sociodemographic factors of adults and older adults attending a middle- and high-complexity audiology service.

\section{METHODS}

This paper was approved by the Research Ethics Committee of the Universidade Federal de Minas Gerais - UFMG, Brazil, under evaluation report no. CAAE 25014913.0.0000.5149. To carry out the research, its participants were informed about the voluntary nature of the study, its objectives, methodological procedures, risks, and benefits. After then, the patients were invited to sign the informed consent form.

This is an exploratory study with a probabilistic sample comprising 152 adults and older adults attending the Department of Audiology of the Hospital São Geraldo, part of the Hospital das Clínicas at UFMG.

The sample was established by sample calculation, considering the yearly flow of 7,680 people who attend the outpatient centers that make up the Department of Audiology of the Hospital das Clínicas at UFMG the Hearing Health Care Service and the Audiology Outpatient Center. The sample calculation considered a simple random sample with a $99 \%$ confidence level. The sample was stratified by the outpatient center 
- 114 people from the Hearing Health Care Service, all of them HA users, and 38 patients of the Audiology Outpatient Center participated in the research.

The Hearing Health Care Service is a high-complexity one, which since 2003 has been providing appointments and examinations to all the population of the state of Minas Gerais to diagnose a hearing disability, fit and replace HA, and furnish hearing rehabilitation. The Audiology Outpatient Center conducts the auditory assessment of people referred by Health Centers and Reference Secondary Units, and patients attending the Hospital São Geraldo.

The criteria for inclusion in the study were their being at least 18 years old, attending either the Hearing Health Care Service or the Audiology Outpatient Center, undergoing the pure-tone threshold audiometry and acoustic immittance on the day of data collection, agreeing to participate in the study, and signing the informed consent form. The participants that did not answer all the questionnaires and were not neurologically or cognitively apt to understand the questions in the instruments, as assessed with the information given by their companions or in their medical records, were excluded.

A questionnaire developed by the researchers, with questions on sociodemographic data (age, sex, schooling level, place of residence) and reasons for making the auditory examination, was used to characterize the study's participants. They also answered the Brazil Economic Classification Criteria (CCEB, its Portuguese acronym ${ }^{13}$, in an interview with the researchers.

The people were classified as older adults, according to the criterion proposed by WHO, which so considers those 60 years old or more in developing countries and 65 years old or more in developed countries ${ }^{14}$.

The results from the pure-tone threshold audiometry and tympanometry were collected in the medical records. The audiometric thresholds were classified in audiometric type ${ }^{15}$, degree ${ }^{16}$, and configuration ${ }^{17}$. The hearing losses were also classified as disabling or non-disabling. According to $\mathrm{WHO}$, disabling hearing loss in adults is defined as the permanently increased auditory threshold in the best ear to levels over 40 $\mathrm{dBHL}$, using pure-tones at the frequencies of $0.5,1$, 2 , and $4 \mathrm{KHz}^{18}$. The results of the tympanometry were classified with criteria proposed in the literature ${ }^{19}$.

The aspects of functioning and disability of those attending the Department of Audiology were analyzed with the ICF'.

The information in the ICF is organized in two parts with two components each.

- Part one - Functioning and Disability:

- Body Functions and Structures: The codes used for body functions are preceded by the letter "b" (body function), and those of body structures, by the letter "s" (structure).

- Activities and Participation: The codes in this component are preceded by the letter " $d$ " (domain) and are assessed with the performance and capacity qualifiers.

- Part two - Environmental Factors has information on:

- Environmental Factors: These are represented by codes beginning with the letter " $e$ " (environment).

- Personal Factors: These are not classified in the ICF. Each ICF component has domains with coded categories. They are accompanied by qualifiers that specify the magnitude of the functioning or disability and assess whether the environmental factors are facilitators or barriers.

In this study, categories of the Body Functions, Activities and Participation, and Environmental Factors were selected, based on the hearing loss core set proposed in the literature ${ }^{3}$.

The codes and classification of the ICF components were also chosen based on the questions and information collected from the protocols that assess the restrictions to hearing participation, namely, the Hearing Handicap Inventory for Adults - HHIA ${ }^{20}$ and Hearing Handicap Inventory for the Elderly - $\mathrm{HHIE}^{21}$, which were individually administered in an interview. The code classification followed the criteria published in the literature ${ }^{6}$ (Figure 1). 


\begin{tabular}{|l|l|}
\hline Domains & Categories \\
\hline \multirow{5}{*}{ Body Functions } & b1560 Auditory perception \\
\hline & b230 Hearing functions \\
\hline & b235 Vestibular functions \\
\hline b240 Sensations associated with hearing and vestibular function \\
\hline \multirow{5}{*}{ Activities and Participation } & d115 Listening \\
\hline & d310 Communicating with and receiving spoken messages \\
\hline d315 Communicating with and receiving nonverbal messages \\
\hline & d330 Speaking \\
\hline d350 Conversation \\
\hline d360 Using communication devices and techniques \\
\hline d730 Relating with strangers \\
\hline & d750 Informal social relationships \\
\hline d760 Family relationships \\
\hline & d920 Recreation and leisure \\
\hline E125 Products and technology for communication \\
\hline environmental Factors & e250 Sound \\
\hline e310 Immediate family \\
\hline e320 Friends \\
\hline e355 Health professionals \\
\hline & e580 Health services, systems, and policies \\
\hline
\end{tabular}

Figure 1. Categories of the International Classification of Functioning, Disability, and Health selected for the research, based on the answers to the Hearing Handicap Inventory for Adults and Hearing Handicap Inventory for the Elderly

All the variables of the study were descriptively analyzed, with the distribution of absolute and relative frequency of the categorical variables and numerical synthesis of the continuous variables. The results of the analyses were organized in tables and graphs in Excel, with the whole sample, stratified by the department they attended. The data were analyzed with the Statistical Package for the Social Sciences (SPSS), version 21.0.

\section{RESULTS}

This study had the participation of 152 people, most of them females (53.9\%) and older adults (59.2\%), referred for auditory assessment by an otorhinolaryngologist $(74.8 \%)$ and attending the Hearing Health Care Service (75\%). Their mean age was 61.8 years (minimum 18 and maximum 92 years old). Regarding the participants' schooling level, the mean number of years attending school was 5.9 (minimum of zero and maximum of 16 years). The sociodemographic and auditory assessment referral data are shown in Table 1. 
Table 1. Description of the sociodemographic characteristics of the research's participants attending a public audiology service

\begin{tabular}{llcc}
\hline Characteristics & & $\mathbf{N}$ & $\%$ \\
\hline Sex & Females & 82 & 53.9 \\
& Males & 70 & 46.1 \\
& Total & 152 & 100.0 \\
\hline Life cycle & Adult & 62 & 40.8 \\
& Older adult & 90 & 59.2 \\
& Total & 152 & 100.0 \\
\hline Residence & Belo Horizonte & 96 & 63.2 \\
& Metropolitan Region & 41 & 27.0 \\
& Others & 15 & 9.9 \\
& Total & 152 & 100.0 \\
\hline CCEB & Classes A and B & 42 & 27.7 \\
& Class C & 85 & 55.9 \\
& Class D & 25 & 16.4 \\
& Total & 152 & 100.0 \\
\hline Health care service & Hearing Health Care Service & 114 & 75.0 \\
& Audiology Outpatient Center & 38 & 25.0 \\
& Total & 152 & 100.0 \\
\hline \multirow{2}{*}{ Referred by } & Speech-language-hearing & 25 & 16.4 \\
& therapist & 113 & 74.4 \\
& Otorhinolaryngologist & 14 & 9.3 \\
& Others & 152 & 100.0 \\
\hline Total & 17 & 11.2 \\
& Yes & 135 & 88.8 \\
& No & 152 & 100.0 \\
\hline & Total & &
\end{tabular}

Legend: CCEB = Brazil Economic Classification Criteria, $N=$ number of participants

* The numbers in the information vary due to missing data

Concerning the auditory complaints, $82 \%$ of the participants reported difficulties to hear; the second most recurrent complaint was tinnitus (34.7\%). The following reasons to perform an auditory assessment were also informed: dizziness (23.3\%), aural fullness $(8.7 \%)$, perforated tympanic membrane $(8 \%)$, otalgia (6\%), and other causes (6\%). Each participant could report more than one reason to undergo auditory examinations.

The results of the pure-tone threshold audiometry showed that $63.2 \%$ of the participants attending the
Department of Audiology had incapacitating hearing loss. As for the type of hearing loss, the most frequent ones among the patients of the Hearing Health Care Service were sensorineural and mixed. Most of the participants from the Audiology Outpatient Center did not have hearing loss - when they did, the most frequent one was mixed. Most of the participants from the Hearing Health Care Service had moderated hearing loss, while those from the Audiology Outpatient Center had a normal degree (Table 2). 
Table 2. Characteristics of the results of the pure-tone threshold audiometry of the participants of the research attending a public audiology service

\begin{tabular}{lcccccccc}
\hline \multirow{2}{*}{ Characteristics } & \multicolumn{3}{c}{ Hearing Health Care Service } & \multicolumn{3}{c}{ Audiology Outpatient Center } \\
\cline { 2 - 9 } & \multicolumn{2}{c}{ Right Ear } & \multicolumn{2}{c}{ Left Ear } & Right Ear & Left Ear \\
\cline { 2 - 9 } Type of loss & $\mathbf{N}$ & $\%$ & $\%$ & N & $\%$ & N & $\%$ \\
No loss & 7 & 6.1 & 5 & 4.4 & 22 & 57.9 & 17 & 44.7 \\
Sensorineural & 88 & 77.2 & 84 & 73.7 & 6 & 15.8 & 8 & 21.1 \\
Conductive & 2 & 1.8 & 4 & 3.5 & 0 & 0.0 & 5 & 13.2 \\
Mixed & 17 & 14.9 & 21 & 18.4 & 10 & 26.3 & 8 & 21.1 \\
Total & 114 & 100.0 & 114 & 100.0 & 38 & 100.0 & 38 & 100.0 \\
\hline Degree of loss & & & & & & & & \\
Normal & 7 & 6.1 & 5 & 4.4 & 22 & 57.9 & 17 & 44.7 \\
Mild & 23 & 20.2 & 22 & 19.3 & 2 & 5.3 & 8 & 21.1 \\
Moderate & 43 & 37.7 & 38 & 33.3 & 7 & 18.4 & 9 & 23.7 \\
Moderately Severe & 22 & 19.3 & 29 & 25.4 & 2 & 5.3 & 1 & 2.6 \\
Severe & 15 & 13.2 & 16 & 14.0 & 4 & 10.5 & 3 & 7.9 \\
Profound & 4 & 3.5 & 4 & 3.5 & 1 & 2.6 & 0 & 0.0 \\
Total & 114 & 100.0 & 114 & 100.0 & 38 & 100.0 & 38 & 100.0 \\
\hline Configuration of the loss & & & & & & & & \\
Upsloping & 1 & 0.9 & 1 & 0.9 & 2 & 5.3 & 0 & 0.0 \\
Horizontal & 27 & 23.7 & 23 & 20.2 & 23 & 60.5 & 18 & 47.3 \\
Slightly downsloping & 35 & 30.7 & 44 & 38.6 & 6 & 15.8 & 8 & 21 \\
Sharply downsloping & 39 & 34.2 & 31 & 27.2 & 4 & 10.5 & 6 & 15.8 \\
Ramp downsloping & 6 & 5.3 & 8 & 7.0 & 1 & 2.6 & 2 & 5.3 \\
U-shaped & 1 & 0.9 & 2 & 1.8 & 0 & 0.0 & 0 & 0.0 \\
Inverted U-shaped & 5 & 4.3 & 4 & 3.4 & 2 & 5.3 & 2 & 5.3 \\
Notch & 0 & 0.0 & 1 & 0.9 & 0 & 0.0 & 2 & 5.3 \\
Total & 114 & 100.0 & 114 & 100.0 & 38 & 100.0 & 38 & 100.0 \\
\hline
\end{tabular}

Legend: $\mathrm{N}=$ number of participants

In the tympanometry assessment, most of the participants $(86 \%)$ had a type A tympanometric curve in both ears. The types B (4\%), C (2\%), Ad (2\%), and As $(0.7 \%)$ tympanometric curves were also found.

In the classification of functioning and disability of the participants of the research, employing the ICF
Body Functions domain, it was observed that regarding auditory perception (b1560) and hearing functions (b230) most of the participants from the Hearing Health Care Service had a mild or moderate disability, whereas most of the participants from the Audiology Outpatient Center did not have a disability (Table 3). 
Table 3. Distribution (\%) of the qualifiers related to Body Function in the International Classification of Functioning, Disability, and Health of the research's participants attending a public audiology service

\begin{tabular}{|c|c|c|c|c|c|c|c|c|}
\hline \multirow[b]{2}{*}{$\begin{array}{l}\text { Health care } \\
\text { department }\end{array}$} & \multirow[b]{2}{*}{ ICF categories } & \multicolumn{7}{|c|}{ Qualifiers } \\
\hline & & No disability & $\begin{array}{c}\text { Mild } \\
\text { disability }\end{array}$ & $\begin{array}{l}\text { Moderate } \\
\text { disability }\end{array}$ & Disability & $\begin{array}{l}\text { Complete } \\
\text { disability }\end{array}$ & Unspecified & Total (\%) \\
\hline \multirow{3}{*}{$\begin{array}{l}\text { Hearing } \\
\text { Health Care } \\
\text { Service }\end{array}$} & b1560 Auditory perception & 1.8 & 41.2 & 34.2 & 18.4 & 4.4 & 0.0 & 100.0 \\
\hline & b235 Vestibular functions & 86.0 & 0.0 & 0.0 & 0.0 & 0.0 & 14.0 & 100.0 \\
\hline & $\begin{array}{l}\text { b240 Sensations associated with } \\
\text { hearing and vestibular function }\end{array}$ & 86.0 & 0.0 & 0.0 & 0.0 & 0.0 & 14.0 & 100.0 \\
\hline \multirow{3}{*}{$\begin{array}{l}\text { Audiology } \\
\text { Outpatient } \\
\text { Center }\end{array}$} & b230 Hearing functions & 50 & 18.4 & 26.3 & 5.3 & 0.0 & 0.0 & 100.0 \\
\hline & b235 Vestibular functions & 55.3 & 0.0 & 2.6 & 0.0 & 0.0 & 42.1 & 100.0 \\
\hline & $\begin{array}{l}\text { b240 Sensations associated with } \\
\text { hearing and vestibular function }\end{array}$ & 63.2 & 0.0 & 5.3 & 0.0 & 0.0 & 31.6 & 100.0 \\
\hline
\end{tabular}

Legend: ICF = International Classification of Functioning, Disability, and Health

In the Activities and Participation domain, it was observed in the performance assessment (related to what the person does in their usual living environment) that the participants attending the Hearing Health Care Service achieved better results (no difficulty) in codes d330 Speaking (83.3\%), d315 Communicating with and receiving nonverbal messages (65.8\%), and d760
Family relationships (65.1\%). The participants attending the Audiology Outpatient Center achieved better results in the activities of codes d330 Speaking (94.7\%), d315 Communicating with and receiving nonverbal messages (89.5\%), and d310 Communicating with and receiving spoken messages $(73.7 \%)$, as shown in Table 4.

Table 4. Distribution (\%) of the qualifiers related to Activities and Participation in the International Classification of Functioning, Disability, and Health of the research's participants attending a public audiology service

\begin{tabular}{|c|c|c|c|c|c|c|c|c|c|c|c|c|}
\hline \multirow{3}{*}{$\begin{array}{l}\text { Health care } \\
\text { department }\end{array}$} & \multirow{3}{*}{ ICF categories } & \multicolumn{11}{|c|}{ Qualifiers } \\
\hline & & \multicolumn{2}{|c|}{ No difficulty } & \multicolumn{2}{|c|}{ Mild difficulty } & \multicolumn{2}{|c|}{$\begin{array}{l}\text { Moderate } \\
\text { difficulty }\end{array}$} & \multicolumn{2}{|c|}{ Severe difficulty } & \multicolumn{2}{|c|}{$\begin{array}{l}\text { Complete } \\
\text { difficulty }\end{array}$} & \multirow[t]{2}{*}{$\begin{array}{c}\text { Total } \\
(\%)\end{array}$} \\
\hline & & $\mathbf{P}$ & C & $\mathbf{P}$ & C & $\mathbf{P}$ & C & $\mathbf{P}$ & C & $\mathbf{P}$ & C & \\
\hline \multirow{10}{*}{$\begin{array}{l}\text { Hearing } \\
\text { Health Care } \\
\text { Service }\end{array}$} & d115 Listening & 47.4 & 2.6 & 22.8 & 36.8 & 24.6 & 37.7 & 0.0 & 17.5 & 0.0 & 5.3 & 100.0 \\
\hline & $\begin{array}{l}\text { d310 Communicating with and receiving } \\
\text { spoken messages }\end{array}$ & 49.1 & 27.2 & 21.1 & 21.9 & 25.4 & 31.6 & 4.4 & 14.0 & 0.0 & 14.0 & 100.0 \\
\hline & $\begin{array}{l}\text { d } 315 \text { Communicating with and receiving } \\
\text { nonverbal messages }\end{array}$ & 65.8 & 57.0 & 18.4 & 15.8 & 10.5 & 14.0 & 5.3 & 9.6 & 0.0 & 3.5 & 100.0 \\
\hline & d330 Speaking & 83.3 & 78.1 & 11.4 & 10.5 & 2.6 & 5.3 & 2.6 & 4.4 & 0.0 & 1.8 & 100.0 \\
\hline & d350 Conversation & 50.9 & 22.8 & 23.7 & 25.4 & 21.1 & 30.7 & 4.4 & 15.8 & 5.3 & 5.3 & 100.0 \\
\hline & $\begin{array}{l}\text { d360 Using communication devices and } \\
\text { techniques }\end{array}$ & 47.4 & 14.0 & 25.4 & 28.9 & 19.3 & 31.6 & 7.9 & 19.3 & 0.0 & 5.3 & 100.0 \\
\hline & d730 Relating with strangers & 50 & 21.9 & 19.3 & 21.9 & 22.8 & 33.3 & 7.9 & 17.5 & 0.0 & 5.3 & 100.0 \\
\hline & d750 Informal social relationships & 52.6 & 21.1 & 20.2 & 23.7 & 20.2 & 33.3 & 7.0 & 16.7 & 0.0 & 5.3 & 100.0 \\
\hline & d760 Family relationships & 56.1 & 22.8 & 22.8 & 24.6 & 15.8 & 31.6 & 5.3 & 15.8 & 0.0 & 5.3 & 100.0 \\
\hline & d920 Recreation and leisure & 48.2 & 22.8 & 20.2 & 21.1 & 22.8 & 33.3 & 8.8 & 17.5 & 0.0 & 5.3 & 100.0 \\
\hline \multirow{10}{*}{$\begin{array}{l}\text { Audiology } \\
\text { Outpatient } \\
\text { Center }\end{array}$} & d115 Listening & 63.2 & 50 & 13.2 & 18.4 & 23.7 & 26.3 & 0.0 & 5.3 & 0.0 & 0.0 & 100.0 \\
\hline & $\begin{array}{l}\text { d310 Communicating with and receiving } \\
\text { spoken messages }\end{array}$ & 73.7 & 65.8 & 18.4 & 10.5 & 7.9 & 23.7 & 0.0 & 0.0 & 0.0 & 0.0 & 100.0 \\
\hline & $\begin{array}{l}\text { d315 Communicating with and receiving } \\
\text { nonverbal messages }\end{array}$ & 89.5 & 78.9 & 7.9 & 10.5 & 2.6 & 10.5 & 0.0 & 0.0 & 0.0 & 0.0 & 100.0 \\
\hline & d330 Speaking & 94.7 & 94.7 & 0.0 & 0.0 & 5.3 & 5.3 & 0.0 & 0.0 & 0.0 & 0.0 & 100.0 \\
\hline & d350 Conversation & 60.5 & 52.6 & 13.2 & 15.8 & 26.3 & 26.3 & 0.0 & 5.3 & 0.0 & 0.0 & 100.0 \\
\hline & $\begin{array}{l}\text { d360 Using communication devices and } \\
\text { techniques }\end{array}$ & 55.3 & 52.6 & 21.1 & 15.8 & 18.4 & 26.3 & 5.3 & 5.3 & 0.0 & 0.0 & 100.0 \\
\hline & d730 Relating with strangers & 57.9 & 44.7 & 15.8 & 21.1 & 26.3 & 28.9 & 0.0 & 5.3 & 0.0 & 0.0 & 100.0 \\
\hline & d750 Informal social relationships & 60.5 & 55.3 & 21.1 & 13.2 & 18.4 & 26.3 & 0.0 & 5.3 & 0.0 & 0.0 & 100.0 \\
\hline & d760 Family relationships & 60.5 & 55.3 & 21.1 & 13.2 & 18.4 & 26.3 & 0.0 & 5.3 & 0.0 & 0.0 & 100.0 \\
\hline & d920 Recreation and leisure & 57.9 & 50.0 & 21.1 & 15.8 & 21.1 & 28.9 & 0.0 & 5.3 & 0.0 & 0.0 & 100.0 \\
\hline
\end{tabular}

Legend: ICF = International Classification of Functioning, Disability, and Health, $\mathrm{C}=$ capacity, $\mathrm{P}=$ performance 
Regarding the Environmental Factors, most of the codes were considered facilitators; only code e250 Sound, related to environmental noise, was considered a barrier.

For most participants attending the Hearing Health Care Service, using HA (assessed with code e125 Products and technology for communication) was a mild (29.8\%) or complete facilitator (27.2\%). Code e250 Sound was assessed by most of these participants as a mild (39.5\%) or moderate barrier (31.6\%). As for most participants attending the Audiology Outpatient Center, e250 Sound was not considered a barrier (47.4\%). For most of those attending both audiology services assessed, the environmental factors related to codes e320 Friends, e355 Health professionals, and e580 Health services, systems, and policies were complete facilitators (Table 5).

Table 5. Distribution (\%) of the qualifiers related to Environmental factors in the International Classification of Functioning, Disability, and Health of the research's participants attending a public audiology service

\begin{tabular}{|c|c|c|c|c|c|c|c|c|}
\hline \multirow{2}{*}{$\begin{array}{l}\text { Health care } \\
\text { department }\end{array}$} & \multirow[b]{2}{*}{ ICF categories } & \multirow{2}{*}{$\begin{array}{l}\text { Barrier (B) or } \\
\text { Facilitator (F) }\end{array}$} & \multicolumn{6}{|c|}{ Qualifiers } \\
\hline & & & None & Mild & Moderate & $\begin{array}{c}\text { Severe/ } \\
\text { Considerable }\end{array}$ & Complete & Total (\%) \\
\hline \multirow{6}{*}{$\begin{array}{l}\text { Hearing Health } \\
\text { Care Service }\end{array}$} & $\begin{array}{l}\text { e125 Products and technology } \\
\text { for communication }\end{array}$ & $\mathrm{F}$ & 1.8 & 29.8 & 23.7 & 17.5 & 27.2 & 100.0 \\
\hline & e250 Sound & B & 7.9 & 39.5 & 31.6 & 14.9 & 6.1 & 100.0 \\
\hline & e310 Immediate family & $\mathrm{F}$ & 0.0 & 10.5 & 17.5 & 17.5 & 54.4 & 100.0 \\
\hline & e320 Friends & $\mathrm{F}$ & 0.0 & 9.6 & 19.3 & 19.3 & 51.8 & 100.0 \\
\hline & e355 Health professionals & $\mathrm{F}$ & 0.0 & 2.6 & 9.6 & 32.5 & 55.3 & 100.0 \\
\hline & $\begin{array}{l}\text { e580 Health services, } \\
\text { systems, and policies }\end{array}$ & $\mathrm{F}$ & 0.0 & 2.6 & 9.6 & 32.5 & 55.3 & 100.0 \\
\hline \multirow{6}{*}{$\begin{array}{l}\text { Audiology } \\
\text { Outpatient } \\
\text { Center }\end{array}$} & $\begin{array}{l}\text { e125 Products and technology } \\
\text { for communication }\end{array}$ & $\mathrm{F}$ & 94.7 & 0.0 & 0.0 & 2.6 & 2.6 & 100.0 \\
\hline & e250 Sound & B & 47.4 & 26.3 & 21.1 & 5.3 & 0.0 & 100.0 \\
\hline & e310 Immediate family & $\mathrm{F}$ & 0.0 & 10.5 & 21.1 & 7.9 & 60.5 & 100.0 \\
\hline & e320 Friends & $\mathrm{F}$ & 0.0 & 10.5 & 18.4 & 10.5 & 60.5 & 100.0 \\
\hline & e355 Health professionals & $\mathrm{F}$ & 0.0 & 0.0 & 7.9 & 18.4 & 73.7 & 100.0 \\
\hline & $\begin{array}{l}\text { e580 Health services, } \\
\text { systems, and policies }\end{array}$ & $\mathrm{F}$ & 0.0 & 0.0 & 7.9 & 18.4 & 73.7 & 100.0 \\
\hline
\end{tabular}

Legend: $\mathrm{B}=$ Barrier, $\mathrm{F}=$ Facilitator, ICF = International Classification of Functioning, Disability, and Health

\section{DISCUSSION}

The characterization of the research's participants revealed that most of the sample was made of older adults - which can be explained by the recent aging process of the Brazilian population ${ }^{22}$. One of the changes caused by this condition is presbycusis, defined as the progressive hearing loss, due to age.

The sample characterization also highlights that most participants were females, which corroborates other national studies that assessed the degree of satisfaction of HA users ${ }^{23,24}$, the functioning of older adults attending a public health service ${ }^{22}$, and the self-perception of voice and hearing changes in active older adults ${ }^{25}$. Women seek health assistance services more often throughout their lives, showing better self-health care indicators, which reflects on a better life expectancy $y^{22,23}$.

Regarding the department, it was observed that more than two thirds of the research's participants attended the Hearing Health Care Service (Table 1). The Hearing Health Care Service of the Hospital das Clínicas/UFMG is an integral part of the Care Network for the Persons with Disabilities established by the Ministry's regulatory law no. 793 , of April 24, 2012. It is a high-complexity service that cares for patients with appointments and examinations scheduled by the Municipal Departments of Health for audiological diagnosis, selection, fitting, and replacement of HA, auditory rehabilitation therapy, and follow-up once or twice a year ${ }^{26}$. 
The study's sample characterization also revealed that most of the participants were from the middle-tolower class - i.e., according to the $\mathrm{CCEB}^{8}$, their mean family income could range from 2.4 to 1.6 minimum wages. This finding agrees with the data published in the 2010 demographic census conducted by the IBGE, which showed that the mean monthly income of the families living in the municipality of Belo Horizonte, MG, Brazil (where $63.2 \%$ of the sample in this study lived) was 1.9 minimum wage ${ }^{2}$.

Of the complaints reported for undergoing auditory assessment, the most frequent ones were difficulties to hear, tinnitus, and dizziness, in this order. The least mentioned ones were perforation of the tympanic membrane and otalgia. This information corroborates a national study that assessed the audiological profile of 217 adults and older adults attending a private audiological diagnosis service in the city of São Paulo. These patients' mean age was 53.4 years, $71.8 \%$ of the sample had sensorineural hearing loss, and the main complaints were hypoacusis $(53.4 \%)$, tinnitus $(50.7 \%)$, and dizziness $(22.1 \%)^{27}$.

Another national study characterized the audiological profile and auditory complaints of 2,145 patients attending a public department of audiology in the city of São Paulo. Different from the present research, which assessed adults and older adults, that study conducted in São Paulo assessed patients of all age groups (mean 20.6 years). The researchers observed that tinnitus, itchy ear, aural fullness, and dizziness occurred more often in people over 18 years old and that the otalgia-related complaints tended to decrease as the age increased ${ }^{28}$.

It was observed in the auditory assessment that almost half of the patients attending the Audiology Outpatient Center had auditory thresholds within normal standards, while more than two thirds of those from the Hearing Health Care Service had sensorineural hearing loss (Table 2). Such findings may be related to the fact that most of the total sample use HA and have presbycusis. The patients from the Audiology Outpatient Center may have undergone auditory assessment not because of hearing difficulties but to investigate hearing-related situations, such as dizziness. This would explain why most of the auditory threshold results were within normal standards in the pure-tone threshold audiometry.

The presence of a sensorineural hearing loss in most of the patients attending the Hearing Health Care Service corroborates other studies conducted in different Hearing Health Care Services ${ }^{23,24,29}$. This finding may be explained by the impairment caused by the sensorineural hearing loss, with permanent damage to the cochlea, hindering the discrimination and intelligibility of sounds, recruiting and reducing the audible range. Hence, the HA helps amplify the sound volume, decreasing the difficulties caused by this type of loss.

Hearing plays an essential role in human communication. Incapacitating hearing loss can cause serious social and professional loss, besides bringing about emotional changes, such as depression and insecurity. The present study observed that most of its participants had incapacitating hearing loss. The HA and auditory rehabilitation are options to try and diminish the negative consequences of this type of hearing loss. The main goal of auditory rehabilitation is to reduce the limitations in oral language comprehension of people with hearing disabilities. The HA, through signal processing, helps to better understand speech in more complex listening environments. Thus, the rehabilitation and HA fitting, which are made available to the patients attending the Hearing Health Care Services, are essential for the person to enjoy the hearing experiences furnished by the environment and be able to effectively communicate ${ }^{30}$.

Using the ICF in the present study made it possible to classify the functioning and disability of the people attended at the Department of Audiology of the Hospital São Geraldo, based on their auditory characteristics. The assessment of the Body Function codes revealed that most of the patients attending the Audiology Outpatient Center did not have a disability in any of the aspects assessed. Unlike these patients, those from the Hearing Health Care Service mostly had either a mild or moderate disability in the aspects assessed with codes b1560 Auditory perception and b230 Hearing functions. The results found for code b230 Hearing functions corroborate an international study that, with the ICF, assessed the impact of unilateral hearing loss in 26 people. In it, this was the most reported code as a problem and one of those that most influenced the activities of daily living ${ }^{31}$.

These findings are also related to the greater probability of the patients from the Hearing Health Care Service having changes in the hearing-related functions, such as sound, tone, and intensity discrimination, sound source localization, sound lateralization, and speech discrimination. By participating in the HA selection and fitting process, these people seek a facilitator to diminish the impacts caused by hearing loss. 
In the Activities and Participation, which assesses performance and capacity, it was observed that a considerable portion of the sample did not have difficulties performing activities related to the codes of this domain. The performance describes what the person does in their usual living environment, representing the social and physical setting where each one lives their daily life. As for capacity, it describes the person's aptitude to carry out tasks or actions.

The data reveal that the participants from the Hearing Health Care Service had their worst performance results in questions related to social relationships, represented by codes d115 Listening, d310 Communicating with and receiving spoken messages, d360 Using communication devices and techniques, and d920 Recreation and leisure (Table 4). These findings corroborate, in part, the results of a study with people with unilateral hearing loss, in which one of the most recurrent codes was d310 Communicating with and receiving spoken messages. In the present study, the activities related to code d350 Conversation were mostly classified as no difficulty, which does not corroborate the data presented in the literature ${ }^{31}$. Likewise, the participants from the Audiology Outpatient Center had a worse performance in questions related to social issues, represented by codes d360 Using communication devices and techniques, d730 Relating with strangers, and d920 Recreation and leisure.

Hearing difficulties cause loss of information in interpersonal contact, difficulties getting informed through the means of communication, and using leisure equipment $^{32}$. Thus, developing therapeutic strategies, instructing on how to use the HA, and following up on the patients in the auditory rehabilitation program are greatly important to improve these patients' performance and decrease their restrictions to participation.

Regarding the Environmental Factors, only the code related to environmental noise, e250 Sound, was considered a barrier. For most of the participants attending the Hearing Health Services, the HA (represented by code e125 Products and technology for communication) was reported as either a mild or complete facilitator. These findings corroborate an international study that used the ICF to describe how environmental and personal aspects influence the social participation of older adults with dual sensory disabilities (sight and hearing). As a result, the availability of social support and the use of assistive devices, such as $\mathrm{HA}$ and glasses, were reported as facilitators for the social participation of the population studied ${ }^{33}$. Another international study - whose objective was to investigate the relationship between hearing loss self-management and the benefits and satisfaction of HA users - verified that participants who reported better self-care with the effects of hearing loss in the aspects of social participation and emotional well-being reported less difficulty to hear in noisy environments and greater satisfaction with the HA. The participants who reported better management in the access to resources and services, participation in decision-making, and monitoring of auditory changes were more likely to have greater satisfaction with the quality of the HA sound ${ }^{34}$. A national study that assessed the satisfaction of $98 \mathrm{HA}$ users attending a public service in the city of Ribeirão Preto, SP, Brazil, showed that these patients were satisfied with and adapted to their HA. In the study, there was no statistically significant relationship between the degree of satisfaction and the sex, age, degree, time of hearing loss, or even time of HA fitting ${ }^{23}$. Another national study, which also assessed the degree of satisfaction of $180 \mathrm{HA}$ users followed up at a public service in Florianópolis, SC, Brazil, revealed that most of the subjects had a high level of satisfaction. It was also observed that subjects with profound sensorineural hearing loss had results with lower satisfaction values ${ }^{24}$. Based on the data presented in the literature and the results of this study, it can be stated that the HA is an important instrument for people with hearing loss and that the assessment of what these users reported as the difficult and easy aspects of the device is relevant in monitoring and intervention to minimize the restriction to participation and the psychoemotional problems caused by hearing loss.

Most of the participants of both health care departments considered the immediate family and friends as complete facilitators. An international study aimed to assess the effectiveness of creating communication strategies and psychosocial exercises for subjects with hearing loss and their spouses (with auditory thresholds within normal standards or with a mild hearing loss). It showed that, after the auditory rehabilitation sessions, the communication between the person with hearing loss and their spouse improved. It was observed that the level of stress decreased, as did the refusals to participate in the auditory rehabilitation group. Six months after the intervention, the participants positively assessed their quality of life ${ }^{35}$. The findings of both this study and the present research show the importance of the relatives' and friends' support to the subjects with 
hearing difficulties and the benefits of interaction to the participants of auditory rehabilitation programs.

The environment to which the subject belongs, its intrinsic characteristics, and the interpersonal relationships developed are greatly important to assess the impacts of hearing loss. Hence, the subject with a more severe degree of hearing loss will not always be the one with the greatest restrictions to participation, the worse assessment of the quality of life and emotional impacts when compared, for instance, with a person with a milder degree of hearing loss. Therefore, the patients' individual experiences must be considered by the professionals responsible for the interventions to achieve optimized results.

The national literature has been advancing in the publication of papers in the field encompassing hearing and ICF as an instrument to classify $36-39$, follow up ${ }^{36,37}$, or aid in therapeutic interventions ${ }^{38,39}$. A national study used the International Classification of Functioning, Disability, and Health for Children and Youth (ICF-CY) to analyze 30 medical records of children and adolescents who had a cochlear implant at a research center in the city of Bauru'. It was observed that most of the participants had no disabilities in Body Function and had difficulties only in school achievement. The presence of noise, the unavailability of technological resources, and not undergoing speech-language-hearing therapy were considered barriers (Environmental Factors) ${ }^{9}$.

The findings of the present research are an advancement in the studies regarding the ICF as a classification to be used in speech-language-hearing therapy. The auditory and non-auditory aspects of adults and older adults in a wide age range were classified. As it is a cross-sectional study, though, it was not possible to discuss the causality of the data presented, but only depict a specific population attending a middle- and high-complexity department of audiology.

\section{CONCLUSION}

Using the ICF made it possible to classify and describe the aspects of functioning and disability related to hearing and the sociodemographic factor of adults and older adults attending a middle- and highcomplexity audiology service.

The findings showed that most of the participants attending the Hearing Health Care Service had a disability in auditory perception and auditory functions. However, such a disability was not a limiting factor for their performance in most of the activities and participations assessed. It was also observed that the use of $\mathrm{HA}$ and the relationships with relatives and friends were considered facilitating environmental factors in these people's interaction with the social setting to which they belong. Most of the people attending the Audiology Outpatient Center, in their turn, did not present any disabilities or difficulties in the activities and participation, and the environment, for them, was a facilitator.

\section{REFERENCES}

1. WHO: World Health Organization. Deafness and hearing loss. [accessed on 2015 Nov 10]. Available at: http://www.who.int/mediacentre/ factsheets/fs300/en/

2. IBGE: Instituto Brasileiro de Geografia e Estatística. Censo demográfico de 2010: Resultados. [accessed on 2015 Nov 9]. Available at: http:// censo2010.ibge.gov.br/resultados

3. Danermark B, Granberg S, Kramer SE, Selb M, Möller $\mathrm{C}$. The creation of a comprehensive and a brief core set for hearing loss using the International Classification of Functioning Disability and Health. Am J Audiol. 2013;22(2):323-8.

4. Alfakir R, Holmes $A E$, Noreen F. Functional performance in older adults with hearing loss: application of the International Classification of Functioning Brief Core Set for Hearing Loss: a pilot study. Int J Audiol. 2015;54(9):579-86.

5. Chisolm TH, Johnson CE, Danhauer JL, Portz LJP, Abrams HB, Lesner $S$ et al. A systematic review of health-related quality of life and hearing aids: final report of the American Academy of Audiology Task Force on the Health-Related Quality of Life Benefits of Amplification in Adults. J Am Acad Audiol. 2007;18(2):151-83.

6. OMS: Organização Mundial de Saúde. CIF: a Classificação Internacional de Funcionalidade, Incapacidade e Saúde. 1. ed. São Paulo: Edusp; 2015.

7. Mueller M, Schuster E, Strobl R, Grill E. Identification of aspects of functioning, disability and health relevant to patients experiencing vertigo: a qualitative study using the International Classification of Functioning, Disability and Health. Health Qual Life Outcomes [journal on the Internet]. 2012 [accessed on 2018 Nov 10]; 10(1):[about 9 p.]. Available at: https://doi. org/10.1186/1477-7525-10-75. 
8. Ramkumar V, Rangasayee R. Studying tinnitus in the ICF framework. Int J Audiol. 2010;49(9):645-50.

9. Morettin M, Cardoso MRA, Delamura AM, Zabeu JS, Amantini RCB, Bevilacqua MC. Use of the International Classification of Functioning, Disability and Health for monitoring patients using cochlear implants. CoDAS. 2013;25(3):216-23.

10. Antunes APA, Silva CSR, Ferreira LP, Palladino RRR. Use of the International Classification of Functioning, Disability and Health in SpeechLanguage-Hearing Therapy: an integrative literature review. Rev. CEFAC. 2019;21(4):e18018.

11. Santos ACM, Silva AMC, Luccia GCP, Botelho C, Riva DRD. Psychosocial hearing disadvantage and associated factors among construction workers in Mato Grosso, Brazil. Rev Bras Epidemiol. 2017;20(3):501-13.

12. Jardim DS, Maciel FJ, Lemos SMA. Disabling hearing loss: analysis of associated factors. Audiol., Commun Res. [journal on the Internet]. 2017 [accessed on 2018 Nov 10]; 22(e1765):[about 9 p.] Available at: http://www.scielo.br/ scielo.php?script $=$ sci_issuetoc $\&$ pid $=2317$ $643120170001 \& \operatorname{lng}=$ en\&nrm $=$ iso.

13. ABEP: Associação Brasileira de Empresas de Pesquisa. Critério de Classificação Econômica Brasil. [accessed on 2015 Oct 9]. Available at: http://www.abep.org/criterio-brasil.

14. WHO: World Health Organization. Active Ageing A Policy Framework. A Contribution of the World Health Organization to the Second United Nations World Assembly on Aging. [accessed on 2020 Aug 19]. Available at: https://extranet.who.int/ agefriendlyworld/wp-content/uploads/2014/06/ WHO-Active-Ageing-Framework.pdf.

15. Silman S, Silverman CA. Basic audiologic testing. In: Silman S, Silverman CA, editors. Auditory diagnosis: principles and applications. San Diego: Singular Publishing Group; 1997. p. 44-52.

16. Lloyd LL, Kaplan H. Audiometric Interpretation: a manual basic audiometry. University Park Press: Baltimore; 1978.

17. Conselho Federal de Fonoaudiologia. Manual de procedimentos em audiometria tonal limiar, logoaudiometria e medidas de imitância acústica [Homepage on the Internet]. 2013 [accessed on 2015 Dez 05]. Available at: http://www. fonoaudiologia.org.br/publicacoes/Manual\%20 de\%20Audiologia\%20.pdf.
18. WHO: World Health Organization. WHO Ear and Hearing Disorders Survey: Protocol (Part 1: Survey methods). [accessed on 2015 Oct 09]. Available at: http://whqlibdoc.who.int/hq/1999/WHO_PBD_ PDH_99.8(1).pdf.

19. Jerger J. Clinical experience with impedance audiometry. Arch Otolaryngol. 1970;92(4):311-24.

20. Aiello CP, Lima II, Ferrari DV. Validade e confiabilidade do questionário de handicap auditivo para adultos. Braz J Otorhinolaryngol. $2011 ; 77(4): 432-8$

21. Ventry IM, Weinstein BE. The hearing handicap inventory for the elderly: a new tool. Ear Hear. 1982;3(3):128-34.

22. Lopes GL, Santos MIPO. Functionality elderly enrolled in a Family Health Strategy unit according to the level of the International Classification of Functioning. Rev Bras Geriatr Gerontol. 2015;18(1):71-83.

23. Moda I, Mantello EB, Reis ACMB, Isaac ML, Oliveira AA, Hyppolito MA. Assessment of hearing aids users' satisfaction - systematic review. Rev. CEFAC. 2013;15(4):778-85.

24. Dell'Antônia SF, Ikino CMY, Carreirão Filho W. Degree of satisfaction of patients fitted with hearing aids at a high complexity service. Braz $\mathrm{J}$ Otorhinolaryngol. 2013;79(5):555-63.

25. Chiossi JSC, Roque FP, Goulart BNG, Chiari BM. Influence of voice and hearing changes in the quality of life of active elderly individuals. Cienc Saúde Coletiva. 2014;19(8):3335-42.

26. Maciel FJ, Januário GC, Henriques CMA, Esteves CC, Silva MA, Carvalho SAS et al. Hearing Health indicators in the State of Minas Gerais: a study by macroregion. Audiol., Commun Res. 2013;18(4):275-84.

27. Jardim IS, Iwahashi JH, Paula VC. Estudo do perfil audiológico de indivíduos atendidos em um serviço de diagnóstico brasileiro. Int Arch Otorhinolaryngol. 2010;14(1):32-7.

28. Samelli AG, Andrade CQ, Pereira MB, Matas CG. Hearing complaints and the audiological profile of the users of an academic health center in the western region of São Paulo. Int Arch Otorhinolaryngol. 2013;17(2):125-30.

29. Mondelli MFCG, Silva LSL. Profile of the patients serviced in a high complexity system. Int Arch Otorhinolaryngol. 2011;15(1):29-34. 
30. Gonsalez ECM, Almeida K. Cross-cultural adaptation of the Speech, Spatial and Qualities of Hearing Scale (SSQ) to Brazilian Portuguese. Audiol., Commun Res. 2015;20(3):215-24.

31. Durisala N, Manchaiah V, Granberg S, Möller K. Determination and classification of the problems experienced by adults with single-sided deafness using ICF classification: an exploratory study using 26 participants. Clin Otolaryngol. 2017;42(3):748-52.

32. Fonseca ICDA, Cruz ECFR, Chaves SPL, Macêdo MLM, Pontes ES, Holanda CM et al. Hearing and language changes in elderly: integrative review. RIASE. 2019;5(1):1708-26.

33. Jaiswal A, Fraser S, Wittich W. Barriers and facilitators that influence social participation in older adults with dual sensory impairment. Front. Educ. 2020;127(5):1-11.

34. Convery E, Keidser G, Hickson L, Meyer C. The relationship between hearing loss self-management and hearing aid benefit and satisfaction. Am J Audiol. 2019;28(2):274-84.

35. Preminger JE, Meeks S. Evaluation of an audiological rehabilitation program for spouses of people with hearing loss. J Am Acad Audiol. 2010;21(5):315-28.

36. Bernardi SA, Pupo AC, Trenche MCB, Barzaghi L. The use of ICF in the monitoring of hearing and language development in children in their first year of life. Rev. CEFAC. 2017;19(2):159-70.

37. Mitra S, Shakespeare T. Remodeling the ICF. Disabil Health J. 2019;12(3):337-9.

38. Prodinger B, Cieza A, Oberhauser C, Bickenbach J, Üstün TB, Chatterji S et al. Toward the International Classification of Functioning, Disability and Health (ICF) rehabilitation set: a minimal generic set of domains for rehabilitation as a health strategy. Arch Phys Med Rehabil. 2016;97(6):875-84.

39. Abdi S, Spann A, Borilovic J, de Witte L, Hawley M. Understanding the care and support needs of older people: a scoping review and categorisation using the WHO international classification of functioning, disability and health framework (ICF). BMC geriatrics [journal on the Internet]. 2019 [accessed on 2020 Aug 20]; 19(1):[about 15 p.]. Available at: https://doi.org/10.1186/s12877-019-1189-9. 